STUDI

FRANCESI

\section{Studi Francesi}

Rivista quadrimestrale fondata da Franco Simone

165 (LV | III) | 2011

LA RAPPRESENTAZIONE DELLA MADRE NELLA

LETTERATURA FRANCESE DEL NOVECENTO a cura di Dario Cecchetti e Michele Mastroianni

\title{
Judith Perrenoud-Wörner, Rire et sacré: la vision humoristique de la vérité dans l'Heptaméron de Marguerite de Navarre
}

\section{Martina Airoldi}

\section{(2) OpenEdition \\ Journals}

\section{Edizione digitale}

URL: http://journals.openedition.org/studifrancesi/4961

DOI: 10.4000/studifrancesi.4961

ISSN: 2421-5856

\section{Editore}

Rosenberg \& Sellier

\section{Edizione cartacea}

Data di pubblicazione: 1 décembre 2011

Paginazione: 629-630

ISSN: 0039-2944

Notizia bibliografica digitale

Martina Airoldi, «Judith Perrenoud-Wörner, Rire et sacré: la vision humoristique de la vérité dans I'Heptaméron de Marguerite de Navarre», Studi Francesi [Online], 165 (LV | III) | 2011, online dal 30 novembre 2015, consultato il 08 janvier 2021. URL: http://journals.openedition.org/studifrancesi/4961 ; DOI: https://doi.org/10.4000/studifrancesi.4961

Questo documento è stato generato automaticamente il 8 janvier 2021.

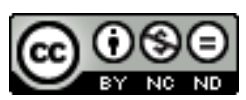

Studi Francesi è distribuita con Licenza Creative Commons Attribuzione - Non commerciale - Non opere derivate 4.0 Internazionale. 


\title{
Judith Perrenoud-Wörner, Rire et sacré: la vision humoristique de la vérité dans l'Heptaméron de Marguerite de Navarre
}

\author{
Martina Airoldi
}

\section{NOTIZIA}

JUDITH PERRENOUD-WÖRNER, Rire et sacré: la vision humoristique de la vérité dans l'Heptaméron de Marguerite de Navarre, Genève, Éditions Slatkine, 2008, pp. 463.

Il lavoro di Judith Perrenoud-Wörner si presenta come studio tematico dell'Heptaméron di Margherite de Navarre, ed è incentrato sulla dimensione umoristica del testo in questione. Come nota l'autrice, infatti, numerose espressioni di gioia, fenomeni di ironia e di comicità ricorrono nelle novelle, edite per la prima volta nel 1549. Prima di addentrarsi nell'analisi del testo Judith Perrenoud-Wörner dedica una prima parte del volume allo studio delle tradizioni legate al riso e alla gioia, al rapporto tra questi ultimi e il sacro. Procedendo cronologicamente, la studiosa si sofferma sulle connotazioni che gioia e riso assumono nella filosofia antica, nella Bibbia e in tutta la tradizione ecclesiastica, fino ad arrivare ai predicatori contemporanei di Marguerite de Navarre. La comicità risulta essere una componente imprescindibile della novella che dovrebbe prefissarsi sia uno scopo terapeutico, sia morale. La seconda parte del volume è poi interamente dedicata allo studio della gioia e del riso all'interno dell'Heptaméron, a partire dal prologo, per giungere successivamente all'analisi delle novelle. Il tema della gioia - stando alle ricerche dell'A. - compare sistematicamente nella cornice che fa da sfondo ai racconti e ai dibattiti fra i personaggi; al contrario l'allegria e la risata compaiono soprattutto nelle novelle, in cui la gioia spirituale lascia spazio ad un tipo di gioia più profana, legata al divertissement e alle vicende amorose. L'ultima parte del volume è invece consacrata allo studio dell'ironia e dell'umorismo che, come nota la 
studiosa, sono centrali al testo. Come sottolinea la stessa Judith Perrenoud-Wörner, l'originalità dell'Heptaméron consiste proprio nell'aver presentato forme differenti di gioia che ritornano continuamente nel testo, quasi a voler sottolineare l'importanza tanto della joie spirituale, quanto di quella profana. 